\title{
Acute-Onset Persistent Olfactory Deficit Resulting From Multiple Overexposures to Ammonia Vapor at Work
}

\author{
Janice C. Prudbomme, DO, MPH, Dennis J. Shusterman, MD, MPH, \\ and Paul D. Blanc, $M D, M S P H$
}

Impaired olfaction (a functional decrement in the sense of smell) is not uncommon. It is estimated that at least 2 million Americans suffer from an impaired sense of smell, although the actual number is probably higher. ${ }^{1}$ The importance of this primary sense should in no way be minimized, since its absence can result in profound consequences. Both personal protection and quality of life can be compromised by impaired olfaction. Intact olfaction provides an excellent warning system for detection of hazardous conditions including smoke from fires, ingestion of spoiled foods, and hazardous materials encountered on the job. An employee lacking intact olfaction could be seriously impaired in certain settings, and indeed might be precluded from selected duties as a result. Even appropriate respiratory protection (ie, air-purifying respirators) might not offer sufficient assurance against toxic exposures because the impaired person would not be able to detect respirator leaks or cartridge breakthrough. ${ }^{2}$ The senses of taste and smell are intertwined; loss of smell can adversely affect gustatory pleasure or, more importantly, can lead to anorexia.

Despite the frequency of irritant upper airway exposures occupationally, ${ }^{3}$ published cases of work-related residual olfactory impairment have frequently lacked documentation of sensory testing. Recognition of the link between irritant exposure and upper airway functional loss is thus important to occupational and general health practice.

We report a case in which persistent hyposmia (reduction in the sense of smell) occurred following an acute industrial exposure to ammonia.

Submitted 2 May 1997.

From the Division of Occupational and Environmental Medicine, University of California, San Francisco. Address reprint requests to Paul Blanc, $M D$, Division of Occupational and Environmental Medicine, University of California, San Francisco, PO Box 0924, San Francisco, CA 94143-0924

\section{Case Report}

A 41-year-old man was in his usual state of good health until 1993, when he was acutely overexposed to an ammonia leak while employed as the owner-operator of a fish-processing plant. The aqueous ammonia involved in the leak was used as a refrigerant in the fish-processing operation. No other irritant gases, including sulfur dioxide, were used as refrigerants in the operation. At the time of the leak, the patient experienced eye and nasal irritation and mild facial skin burning. He avoided mouth breathing and denied experiencing any other acute respiratory symptoms. He spent an entire morning in the vicinity of the leak without wearing respiratory protection. He had previously experienced ammonia leaks with similar but less severe symptoms. No quantitative industrial hygiene measurements of the ammonia concentration were made.

In contrast to previous ammonia exposures, after this incident the patient's nasal symptoms persisted, marked by a sense of nasal stuffiness and intermittent epistaxis continuing for $\mathbf{2}$ weeks. Although the nasal congestion later resolved, he also complained of a concomitant, complete loss of smell that improved only minimally. Whereas some sense of smell did return, he noticed difficulty recognizing previously familiar odors, such as his wife's perfume or freshly mowed grass. Foul or unpleasant odors did not replace normal smells. No other nasal or respiratory tract symptoms, such as rhinorrhea or discharges, persisted. His sense of taste returned to baseline after a transient complaint of a metallic taste.

His senses of hearing and vision remained intact. He reported no history of atopic disease, including allergic rhinitis. He was a lifetime nonsmoker and was on no medications at the time of exposure. There was no history of nasal trauma related to his symptoms. He was examined by an otolaryngologist 6 months after the acute expo- 
sure; no structural abnormalities were observed. A brief trial of intranasal flunisolide was prescribed with no effect.

When he was examined 30 months after his acute exposure, his external nares were patent and without apparent abnormality. Bilateral nasal breathing was without deficit, and there was no sinus tenderness to palpation. Findings of the oropharynx and pulmonary examinations were unremarkable. Assessment of his olfactory detection threshold for phenylmethy carbinol using a quantitative Smell Test Kit (Olfactolab; El Cerrito, Calif) was consistent with hyposmia, yielding an olfactory threshold of 40 decismels (dS). ${ }^{\star}$ The upper limit of normal (for persons aged 20 to 70 years) on the decismel scale is $25 \mathrm{dS}$; the absolute cutoff for hyposmia is $35 \mathrm{dS}$. Using a standardized diagnostic testing kit - the University of Pennsylvania Smell Identification Kit (UPSIT; Pittsburgh) - he was able to identify correctly only 24 out of 40 possible odors.

\section{Discussion}

This case illustrates acute-onset hyposmia persisting more than 2 years after a transient industrial overexposure to ammonia, superimposed upon multiple previous exposures without earlier subjective sequelae. This case is important for several reasons: (1) ammonia is a particularly common industrial and household chemical, (2) the resultant damage became apparent after a single acute exposure, (3) the medical literature documenting acute olfactory injury following chemical exposure is scant, and (4) this literature in most cases is based upon self-reported olfactory dysfunction rather than objective sensory testing.

It is important to recognize the limitations of our case report, however. Baseline, objective data are not available on our patient's olfactory function. As is common in the field of occupational medicine, precise, quantified exposure data are also lacking. Endoscopic evaluation can detect mucosal changes consistent with inflammation or irritation, although the otolaryngologist's report did not suggest such pathologic changes. Additionally, no

\footnotetext{
"Decismels (dS) are defined as 20 log (test concentration/reference concentration), where the reference concentration is the average odor threshold in a reference population. Thus, a score of $40 \mathrm{dS}$ indicates that the patient's odor detection threshold was at a test concentration 100 times the population average for the compound employed.
}

nasal biopsy or lavage was performed to aid in the exclusion of inflammatory or infectious cofactors known to impact olfaction adversely.

The occupational importance of olfactory impairment has been recognized in two major reviews. ${ }^{4,5}$ General understanding of this topic can be hampered by the nomenclature used to describe the pathology of deficits, which can be confusing. Three conditions with fairly universal definitions include anosmia (complete absence of the sense of smell), byposmia (diminished ability to detect odorants), and dysosmia (distortion of normal smell). Olfactory impairment following specific occupational exposures has been best documented following chronic exposure to various metals (chromium, nickel, cadmium), solvents, acids, petroleum products, and more recently, acrylate and methacrylate vapors..$^{4-9}$ In contrast, relatively few acute irritant exposures have been associated with olfactory deficits (transient or persistent); these include hydrogen sulfide, hydrogen selenide, sulfuric acid, phosphorus oxychloride, and sulfur dioxide. ${ }^{10-14}$

Ammonia used in the refrigeration process is in a liquid form (ammonium hydroxide or $\mathrm{NH}_{4} \mathrm{OH}$ ). Because of its higher toxicity and flammability or explosive properties, ammonia is now often replaced by less-toxic refrigerants. ${ }^{15,16}$ The concentration of ammonium hydroxide used in refrigeration equipment falls in the range of 9 to 38 ppm..$^{17,18}$

Ammonia can cause immediate irritation and inflammation of the mucosal lining of the upper respiratory tract because it is highly soluble in water. ${ }^{19}$ Consequently, direct olfactory epithelial cell damage could result in impaired olfaction. Nasal irritation is common to anyone who has used ammonia during routine household cleaning. It is important to note that household cleaning products contain approximately 5 to 10 percent ammonia by weight, whereas industrial strength forms can be considerably more concentrated. ${ }^{17,18}$ The nasal mucosa can retain 60 to 80 percent of inhaled ammonia, regardless of concentration..$^{20}$

In certain occupations, especially agriculture, exposure to high levels of anhydrous ammonia is not uncommon. Farmers exposed to ammonia levels ranging from 50 to $200 \mathrm{ppm}$ frequently report nasal congestion. ${ }^{21}$ Similar symptoms have been reported following short-term exposures $(15 \mathrm{~min}$ utes) to anhydrous ammonia averaging $90 \mathrm{ppm}$ and time-weighted-average concentrations rang- 
ing from $11.9 \mathrm{ppm}$ to $52.4 \mathrm{ppm} .^{22}$ Experimental data corroborate the irritating effects of ammonia on the nasal mucosa. Nasal lavage fluid obtained from swine show a dose-response increase in inflammatory cells following exposures of airborne ammonia concentrations ranging from 0 to 100 ppm. ${ }^{23}$ In humans adaptation to the irritant effect of ammonia has been previously described ${ }^{24}$; however, olfaction was not specifically tested.

Interestingly, our patient reported higher exposure to ammonia on previous occasions without major olfactory effects. It is possible some type of adaptation had occurred prior to these earlier events that failed with his final exposure. An alternative explanation might be that his sense of smell was partially compromised from earlier incidents, making his olfactory system less accurate in assessing the severity of subsequent exposure levels.

Although the irritant effects of anhydrous ammonia on both the upper and lower respiratory tracts have been extensively reported in the literature, ${ }^{19,25,26}$ documentation of its effects on olfaction are far less conclusive. Workers at a chemical plant exposed chronically to both sulfur dioxide and ammonia were noted to have higher olfactory thresholds and more self-reported olfactory dysfunction than nonexposed workers; however, similar findings were not observed in workers exposed to ammonia alone. ${ }^{27}$ Similarly, chronic exposure (approximately 14 years) to moderate levels of airborne ammonia (12.5 ppm) had no effect on odor sensitivity in a group of workers at a soda ash factory. ${ }^{28}$ Amoore ${ }^{4}$ cites one incidental report of permanent hyposmia resulting from "chronic" ammonia exposure; however, insufficient detail is available in this report to verify the exposure or outcome.

Hyposmia has been previously reported following single, acute exposures to ammonia in one recent case series. ${ }^{29}$ Of 63 patients seeking care at a nasal dysfunction specialty clinic whose primary complaint was the loss of the sense of smell, 7 (11 percent) had chemically-induced olfactory dysfunction. More interestingly, of these 7 patients, 3 (43 percent) had the onset of their hyposmia following exposure to ammonia. Details of the exposure are briefly described for only one of the three incidents. In the described case, an acute, overwhelming ammonia exposure caused a severe intranasal burn and ultimately irreversible hyposmia. As in our case, there was no response to a trial of nasal steroids. This case series provides additional support that ammonia can adversely impact olfaction.

A syndrome known as the reactive upper airways dysfunction syndrome, or RUDS, might tangentially apply to our case. The syndrome helps categorize persons who experience persistent nasal symptoms, specifically rhinitis and heightened subjective sensitivity to chemical irritants, after a single acute exposure to an upper respiratory tract irritant. ${ }^{30}$ This syndrome is considered analogous to an asthma-like syndrome known as $\mathrm{RADS}$ (reactive airways dysfunction syndrome) that develops in certain persons following acute pulmonary tract irritation. ${ }^{31}$ Symptoms develop after a single (generally, intense) exposure and persist in the absence of additional exposures. Our patient did develop some pertinent nasal symptoms following one of multiple acute exposures to ammonia. Although an olfactory deficit as such has not been incorporated into the clinical syndrome definition of RUDS, ${ }^{30}$ it is a plausible consequence of any persistent inflammatory process.

A major limitation in earlier reports of olfactory impairment following environmental exposure has been the lack of objective, standardized measurements of olfactory function. The two tests used in this case, UPSIT (University of Pennsylvania Smell Identification Test), a qualitative test kit, and OLFACTO-LABS (Quantitative Smell Test Kits) are well-validated ${ }^{32,33}$ and are now widely available.

The upper respiratory tract is inherently susceptible to the toxic effects of airborne irritants. The nasal mucosa and olfactory epithelium are primary targets of water-soluble toxicants, of which ammonia is prototypic. Such exposures and their resulting impairment are likely far more commonly encountered in primary care settings than is generally appreciated. It has recently been reported, for example, that family physicians spend 14 percent of their time dealing with occupational health problems overall. ${ }^{34}$ Upper airway disorders, including irritant-related symptoms, are an important occupational problem among those likely to be encountered. In the same study, 29 percent of physicians specified occupational exposures as a high-priority issue about which more knowledge was needed. Knowledge on olfactory impairment is a particularly needed area of better understanding. 
John E. Amoore, MD, both provided and aided in the translation of several of our referenced foreign articles.

\section{References}

1. Davidson TM, Murphy C. Olfactory impairment. West J Med 1993;159:71-2.

2. Shusterman DJ, Sheedy JE. Occupational and environmental disorders of the special senses. Occup Med 1992;7:515-42.

3. Bascom R, Raford P. Upper airway disorders. In: Rosenstock L, Cullen MR, editors. Textbook of clinical occupational and environmental medicine. Philadelphia: WB Saunders, 1994:315.

4. Amoore JE. Effects of chemical exposure on olfaction in humans. In: Barrow CS, editor. Toxicology of the Nasal Passage. Washington, DC: Hemisphere Publishing, 1986:155-90.

5. Doty RL. A review of olfactory dysfunctions in man. Am J Otolaryngol 1979;1:57-79.

6. Halpern BP. Environmental factors affecting chemoreceptors: an overview. In: Hayes AW, editor. Toxicology of the eye, ear, and other special senses. New York: Raven Press; 1985:195-211.

7. Rose CS, Heywood PG, Costanzo RM. Olfactory impairment after chronic occupational cadmium exposure. J Occup Med 1992;34:600-5.

8. Ahlstrom R, Berglund B, Berglund U, Lindvall $T$, Wennberg A. Impaired odor perception in tank cleaners. Scand J Work Environ Health 1986;12:574-81.

9. Schwartz BS, Doty RL, Monroe C, Frye R, Barker S. Olfactory function in chemical workers exposed to acrylate and methacrylate vapors. Am J Public Health 1989;79:613-8.

10. Meyer J. Wie richt Blausäure? Gasmaske 1935;7: 112.

11. Buchan RF. Industrial selenosis. Occup Med 1947;3: 439-56.

12. Woelk HA. Die traumatische anosmie und ihre Begutachtung. Monatsschr Unfallheilk 1930;37:1-17.

13. MacIntyre I. Prolonged anosmia. Br Med J 1971;2: 709.

14. vonPfander $F$. Anosmie durch einmaliges Einatmen von Schwefeldioxyd. HNO 1959;8:59-60.

15. Refrigeration. In: Kirk RE, Othmer DF, Grayson $M$, Eckroth D. Kirk-Othmer encyclopedia of chemical technology, vol 20. 3rd ed. New York: John Wiley \& Sons; 1982:78-107.

16. Refrigerating plants. In: Parmeggiani L, technical editor. Encyclopaedia of occupational health and safety. 3 rd rev ed. Geneva: International Labour Office, 1983:1910-2.

17. Occupational exposure to ammonia [criteria for a recommended standard].Rockville, $\mathrm{Md}$ : Department of Health, Education, and Welfare, Centers for Disease Control, National Institute for Occupational Safety and Health, 1974. (NIOSH publication no. 74-136.)

18. Environmental Health Criteria 54: Ammonia. Geneva: World Health Organization; 1986.

19. Toxicological profile for ammonia. Atlanta, Ga: Department of Health and Human Services; Public Health Service, Agency for Toxic Substances and Disease Registry, 1990.

20. Landahl HD, Herrmann RG. Retention of vapors and gases in the human nose and lung. Ind $\mathrm{Hyg} \mathrm{Oc}$ cup Med 1950;1:36-45.

21. Donham KJ, Rubino M, Thedell TD, Kammermeyer J. Potential health hazards to agricultural workers in swine confinement buildings. J Occup Med 1977; 19:383-7.

22. Exposure to ammonia during removal of paint from artificial turf - Ohio. MMWR Morb Mortal Wkly Rep 1984;33:567-8.

23. Urbain B, Gustin P, Prouvost JF, Ansay M. Quantitative assessment of aerial ammonia toxicity to the nasal mucosa by use of the nasal lavage method in pigs. Am J Vet Res 1994;55:1335-40.

24. Ferguson WS, Koch WC, Webster LB, Gould JR. Human physiological response and adaption to ammonia. J Occup Med 1977;19:319-26.

25. Documentation of the threshold limit values and biologic exposure indices. 6th ed. Cincinnati: American Conference of Governmental Industrial Hygienists, 1991:58-9.

26. OSHA regulated hazardous substances: health, toxicity, economic and technological data. Volume $1 \mathrm{~A}-1$. Park Ridge, NJ: Noyes Data Corporation; 1990:104-7.

27. Harada N, Dodo H, Fujii M. Olfactory disorder in chemical plant workers exposed to $\mathrm{SO} 2$ and/or NH3. J Sci Labour 1983;59:17-23.

28. Holness DL, Purdham JT, Nethercott JR. Acute and chronic respiratory effects of occupational exposure to ammonia. Am Ind Hyg Assoc J 1989;50:646-50.

29. Davidson TM, Jalowayski AA, Murphy C, Jacobs RD. Evaluation and treatment of smell dysfunction. West J Med 1987;146:434-8.

30. Meggs WJ. RADS and RUDS - the toxic induction of asthma and rhinitis. J Toxicol Clin Toxicol 1994; 32:487-501.

31. Brooks SM, Weiss MA, Bernstein IL. Reactive airways dysfunction syndrome (RADS). Persistent asthma syndrome after high level irritant exposures. Chest 1985;88:376-84.

32. Fortier I, Ferraris J, Mergler D. Measurement precision of an olfactory perception threshold test for use in field studies. Am J Ind Med 1991;20:495-504.

33. Doty RL. The smell identification test ${ }^{\mathrm{TM}}$ administration manual: $3 \mathrm{rd}$ ed. Haddon Heights, NJ: Sensonics, 1995:10-7.

34. Goodwin P, Wall EM, Bajorek M. Occupational medicine content of Oregon family physician practices. J Am Board Fam Pract 1995;8:300-4. 